\title{
Removal of Chromium(VI) Using Chemically Activated Pistachios Seed Shell Carbon and Commercially Available Carbon
}

\author{
M.S. MALAR SELVI ${ }^{1}$, S. AMALA FATIMA RANI ${ }^{2}$ and S. PAULINE SUGANTHI ${ }^{2}$ \\ ${ }^{1}$ Chennai Institute of Technology, Chennai, Tamilnadu, India \\ ${ }^{2} \mathrm{PG}$ and Research Department of Chemistry, Holy Cross College, Trichy-2, Tamilnadu, India \\ malarsampath@gmail.com
}

Received 6 September 2017 / Accepted 9 October 2017

\begin{abstract}
Pistachios seed shell carbon and commercially activated carbon was used for the removal of heavy metals from industrial wastewater have been studied. Pista seed shell carbon is a natural, low cost and eco-friendly adsorbent. Pistachios seed shell carbon was used for the removal of $\mathrm{Cr}$ (VI) from synthetic water. The carbon characteristics was determined by moisture content, ash content, matter soluble in both water and acid, range of $\mathrm{pH}$, decolourising power, iron content, ion exchange capacity and zero point charge. The adsorbents were tested by using batch experiments under controlled conditions. The effect of various experimental parameters were examined such as equilibrium time, function of $\mathrm{pH}$, adsorbent dose, concentration, temperature, agitation speed, various adsorbent size were investigated. The obtained equilibrium adsorption data is fitted to the linear forms of Freundlich, Langmuir, Temkin adsorption isotherms. The carbon was characterized by x-ray diffraction (XRD), Fourier transform-infrared spectroscopy (FT-IR) before and after adsorption. These results indicate that PSSC is a very good adsorbent than CAC and it can be used for the development of highly efficient adsorbent for the separation of heavy metals from synthetic water.
\end{abstract}

Keywords: Adsorption, Characterization, Pistachios seed shell carbon, Langmuir isotherm, Freundlich isotherm

\section{Introduction}

Every organism is surrounded by materials and forces which contribute its environment, from which it must be, derive its needs. Environment creates favourable conditions for the existence and development of living organisms ${ }^{1}$. Any unit that includes all of the organisms in a given area interacting with the physical environment so that a flow of energy leads to clearly defined trophic structure, biotic diversity and material cycles within the system is an Environment ${ }^{2}$. The unfavourable alteration of our surroundings" is known as environmental pollution. It changes the quality of air, water and land which interferes with the health of human and others life on earth ${ }^{1}$. A toxic heavy metal is any relatively dense metal or metalloid that is noted for its potential toxicity, especially in environmental contexts ${ }^{3}$. 
Water-insoluble chromium(III) compounds and chromium metal are not considered a health hazard, while the toxicity and carcinogenic properties of chromium(VI) have been known for a long time ${ }^{4}$. Over exposure to chromium can occur in welders and other workers in the metallurgical industry, persons taking chromium-containing dietary supplements, patients who have received metallic surgical implants and individuals who ingest chromium salts ${ }^{5}$. The increase in removal efficiency with contact time is due to increase in surface area and hence more active sites are available adsorption ${ }^{6}$. In recent years there are available methods that have been used for advanced wastewater treatment. These are adsorption, chemical oxidation, desalination, chemical coagulation and filtration, etc. The purpose of carbon adsorption is also to remove organic as well as inorganic components in the wastewater. This process aims to compare the capacity of bio-adsorbent with the commercially available carbon, for removal of nickel, a toxic heavy metal from wastewater by the method of adsorption. Pistachios seed shell carbon (PSSC) and commercially activated carbon (CAC) are used for the removal of $\mathrm{Cr}(\mathrm{VI})$ from synthetic water.

\section{Experimental}

Pistachios seed shell were collected for sufficient quantity and treated with concentrated hydrochloric acid. The material was kept for 24 hours to facilitate charring of material. They were washed with distilled water to remove free acid and in distilled water for several times. And then added a $10 \% \mathrm{NaOH}$ solution and kept for an hour and then filtered. After filtration it was washed with distilled water for several times. It is then dried in a hot air oven at $110^{\circ} \mathrm{C}$ for 3 hours. The second adsorbent used for systematic studies was the commercially available carbon got from precision scientific company.

\section{Spectronic-20-Spectrophotometer}

The spectronic-20-spectrophotometer was used to measure the relative amount of light transmitted, yielding results in transmittance. It is a single beam spectrometer with an overall wavelength range of $340 \mathrm{~nm}$ to $950 \mathrm{~nm}$.

\section{Characterization of PSSC and CAC}

\section{Physicochemical characterizations of both carbons}

The capacity of bio-adsorbent with the commercially available carbon, for removal of chromium, a toxic heavy metal from wastewater by the method of adsorption. Pistachios seed shell carbon (PSSC) and commercially activated carbon (CAC) were used for the removal of $\mathrm{Cr}(\mathrm{VI})$ from synthetic water. The characteristics were determined for PSSC and $\mathrm{CAC}$ by moisture content, ash content, matter soluble in both water and acid, range of $\mathrm{pH}$, decolourising power, iron content, ion exchange capacity and zero point charge (Table 1).

\section{Batch mode studies}

Batch experiments were carried out which included effect time, effect of $\mathrm{pH}$, effect of carbon dosage, to estimate the percentage of chromium adsorbed by both the adsorbents separately. These studies were further verified with Freundlich adsorption isotherm. Regeneration studies were carried out to recover the metal and adsorbent.

\section{Results and Discussion}

\section{Effect of equilibrium time}

Figure 1 shows the effect of equilibrium time on the removal of $\mathrm{Cr}(\mathrm{VI})$ by PSSC and CAC. The removal increases with increase in time and attains equilibrium at third hour for PSSC and CAC respectively. The percentage of removal for PSSC are found to be 86 and 81 for CAC. 
Table 1. Physicochemical characteristics of PSSC and CAC

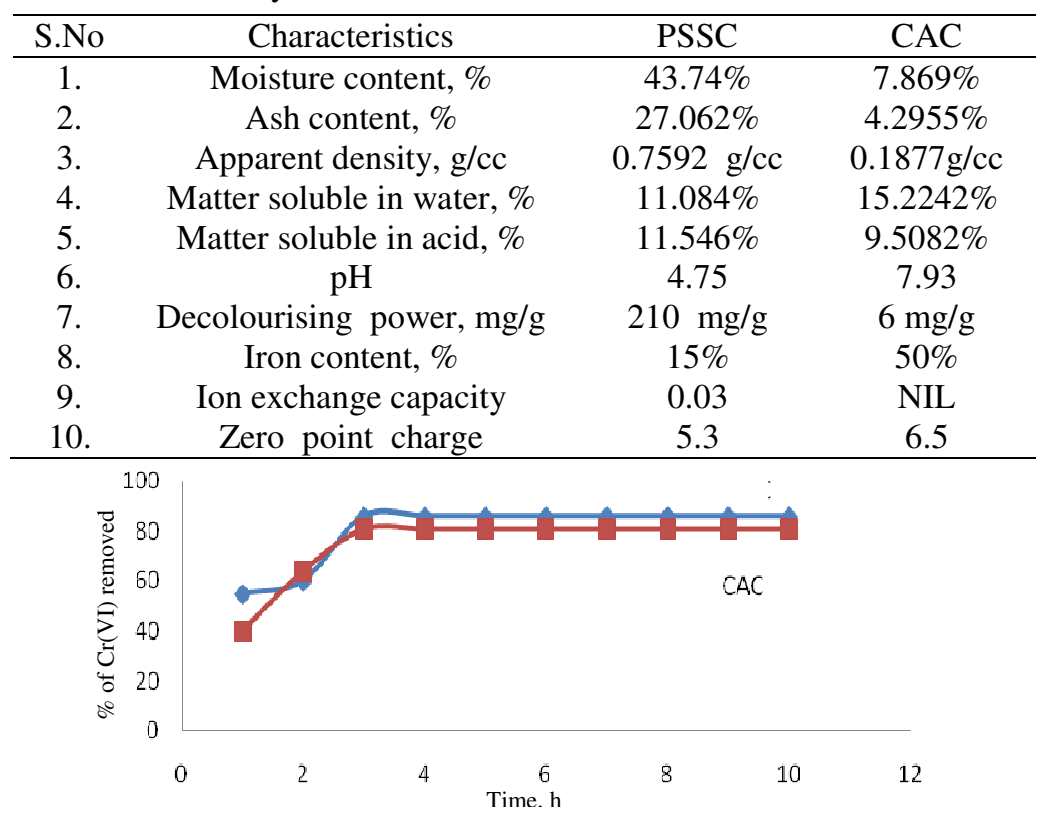

Figure 1. Effect of equilibrium time on the removal of $\mathrm{Cr}(\mathrm{VI})$

\section{Effect of initial concentration}

Figure 2 shows the effect of various concentration on the removal of $\mathrm{Cr}(\mathrm{VI})$ by PSSC and CAC. The removal increase with increase in the various concentration and it attains the highest removal concentration as $10 \mathrm{ppm}$ for PSSC and CAC. The maximum percentage of removal for chromium by PSSC are found to be 81 and 76 for CAC.

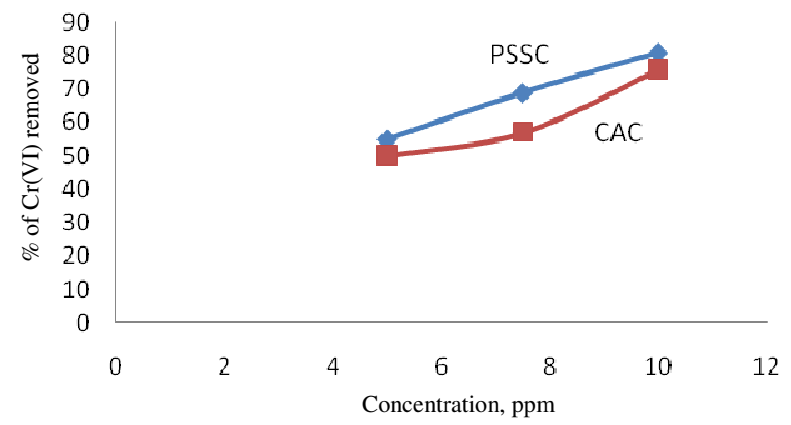

Figure 2. Effect of initial concentration

\section{Effect of $p H$}

Figure 3 shows the effect of $\mathrm{pH}$ on the removal of chromium by PSSC and by CAC with increase in $\mathrm{pH}$, the percentage removal increases and reaches the maximum at $\mathrm{pH} 2$ and 4. The percentage of nickel removed by PSSC is higher by $83 \%$ than that of CAC $72 \%$. The influence of $\mathrm{pH}$ on the removal of chromium may be explained as follows: A pure carbon surface was considered non-polar, but as the $\mathrm{pH}$ increases the adsorbent surface becomes more and more negatively charged and adsorption of $\mathrm{Cr}(\mathrm{VI})$ is more favourable. 


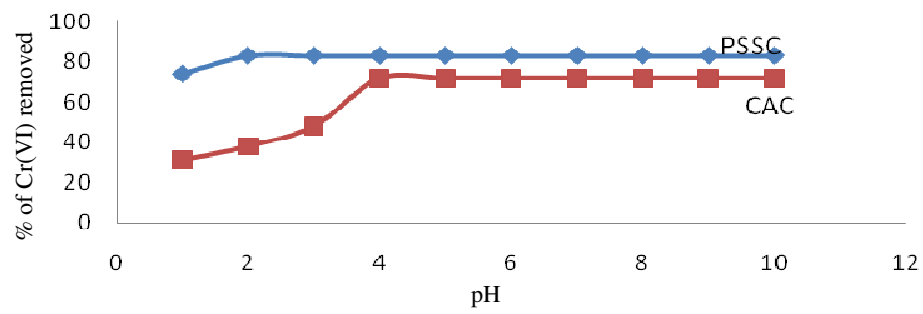

Figure 3. Effect of $\mathrm{pH}$

\section{Effect of carbon dosage}

Figure 4 clearly reveals that the carbon dosage used for removal of chromium using PSSC and CAC which represents the removal of chromium as a function of carbon dosage by PSSC and CAC respectively. It shows that for quantitative removal of chromium from $100 \mathrm{~mL}$ of solutions containing $\mathrm{mg} / \mathrm{L}$. Chromium is a minimum dose of $200 \mathrm{mg}$ of PSSC was required, but for $\mathrm{CAC}$ is a minimum dose of $250 \mathrm{mg}$ was required. The increase in adsorption with increase in adsorbent dose is due to increase in the surface area of the adsorbents and hence more active sites are available for the adsorption of the metal ion ${ }^{7}$.

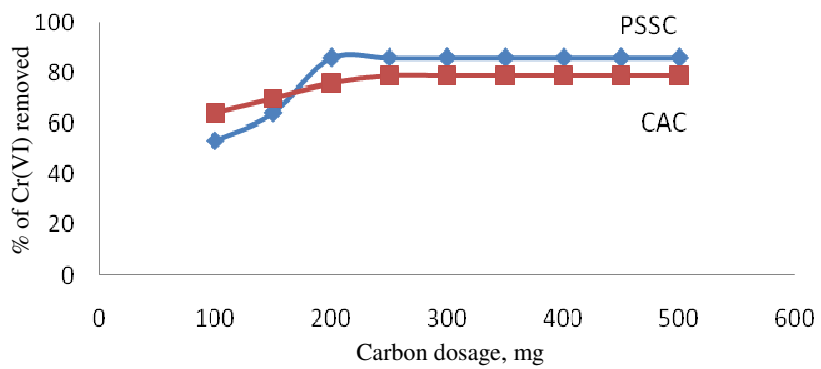

Figure 4. Effect of carbon dosage

\section{Effect of particle size}

Figure 5 shows the lower particle size showed maximum adsorption which maybe due to the availability of larger surface area. Activated carbon has larger surface area (smaller particle size) than carbon (larger particle size). The removal efficiency of $\mathrm{Cr}(\mathrm{VI})$ ions by PSSC and CAC through different sizes. It can be observed that the maximum adsorption efficiency is achieved with particle size $75-150 \mu \mathrm{m}$ for PSSC and $>75 \mu \mathrm{m}$ for CAC. There is a decrease in adsorption efficiency when the particle size is greater. This may be due to the lack of availability of adsorption sites. Smaller particle size showed maximum adsorption, which may be due to the availability of a larger surface area $^{8}$.

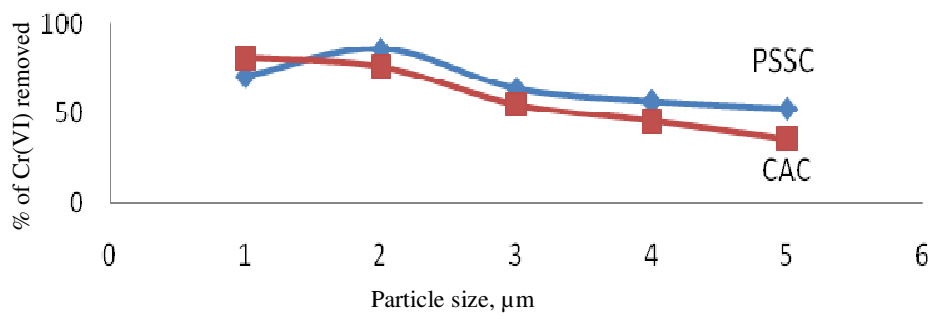

Effect of agitation speed

Figure 5. Effect of particle size

Figure 6 shows the agitation speed less than $120 \mathrm{rpm}$ favours the maximum removal of 
$\mathrm{Cr}(\mathrm{VI})$ by both PSSC and CAC. The maximum removal of $\mathrm{Cr}(\mathrm{VI})$ ions takes place at $100 \mathrm{rpm}$ for $\mathrm{Cr}(\mathrm{VI})$ ions onto both PSSC and CAC.

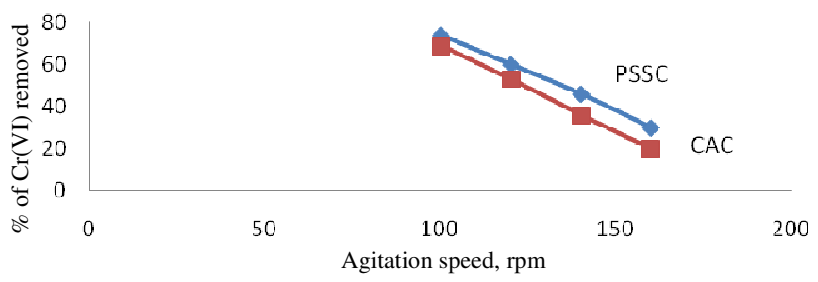

Figure 6. Effect of agitation speed

Figure 7 shows the sorption of $\mathrm{Cr}(\mathrm{VI})$ ions from metal ion solution using the adsorbents like PSSC and CAC were carried out the temperature ranges of $20^{\circ}-60{ }^{\circ} \mathrm{C}$. At low temperatures, the mobility of the metal ions in aqueous solution maybe low; hence, minimum amount of metal ions get removed especially at $30{ }^{\circ} \mathrm{C}$.

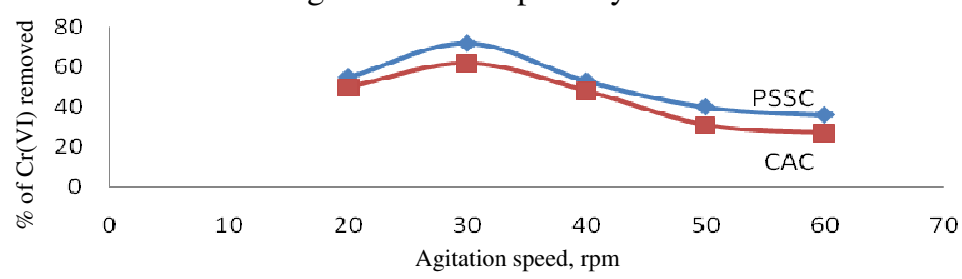

Figure 7. Effect of temperature

\section{Effect of temperature}

\section{Freundlich adsorption isotherm for PSSC and CAC}

Figures 8 and 9 show that Freundlich equation was used to check the effect of adsorption. This equation was useful as a means of data description. Freundlich adsorption isotherm which is the form

$$
\begin{array}{ll}
\log (\mathrm{x} / \mathrm{m}) & =\log \mathrm{k}+1 / \mathrm{n} \log \mathrm{C}_{\mathrm{eq}} \\
\mathrm{k} & =\text { Equilibrium constant } \\
\mathrm{C}_{\mathrm{eq}} & =\text { equilibrium concentration } \\
\mathrm{x} / \mathrm{m} & =\text { amount adsorbed per unit mass }
\end{array}
$$

The $\log (\mathrm{x} / \mathrm{m})$ values are plotted against $\log \mathrm{C}_{\mathrm{eq}}$. The straight line nature of plots indicate that the process follows obey Freundlich adsorption isotherm. The $\mathrm{k}$ values of Freundlich equation was obtained for PSSC and CAC from intercept in the $\log \mathrm{x} / \mathrm{m}$ axis. The sorption intensities $(1 / \mathrm{n})$ were obtained for both the carbons from the slopes of the straight line curves. The $\mathrm{k}$ values were found to be 0.2 and 0.3 for PSSC and CAC respectively. The values of $n$ were calculated for both the carbons. The values of $1<\mathrm{n}<10$ shows favourable adsorption of nickel on both the carbons. The ' $n$ ' values are calculated as 1.2 and 2.5 for PSSC and CAC respectively, which shows that both are having good adsorption capacity.

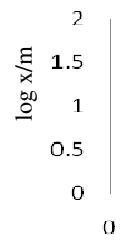

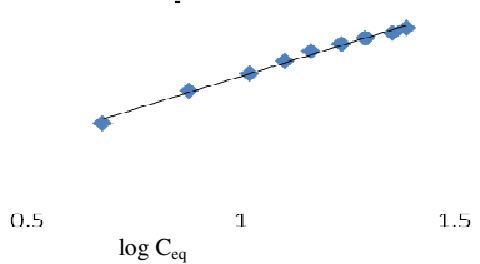

Figure 8. Freundlich adsorption isotherm for PSSC 


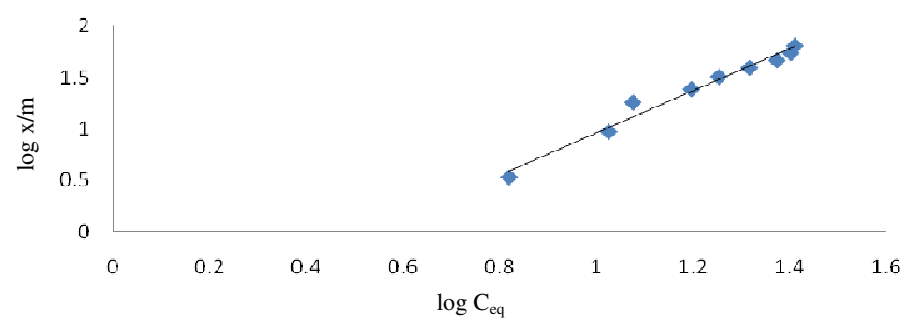

Figure 9. Freundlich adsorption isotherm for CAC

\section{Langmuir adsorption isotherm for PSSC}

Langmuir isotherm (Figure $10 \& 11$ ) governs the monolayer coverage of the adsorbent on the surface of the adsorbent. Langmuir isotherm represents the equilibrium distribution of metal ions between the solid and liquid phases. The Langmuir isotherm is applicable for monolayer sorption onto a surface containing a finite range of indistinguishable sites.

The model assumes uniform energies of sorption onto the surface and no transmigration of adsorbate within the plane of the surface. It is represented as $C_{e}=1 / Q_{0} b+C_{e} / Q_{0}$

$\mathrm{C}_{\mathrm{e}}=$ The equilibrium concentration of the metal ion, $\mathrm{mg} \mathrm{dm}^{-3}$

$\mathrm{Q}_{\mathrm{e}}=$ The amount of metal ion adsorbed at equilibrium, $\mathrm{mg} \mathrm{g}^{-1}$ and $\mathrm{Q}_{\mathrm{o}}$ and $\mathrm{b}$ are Langmuir constants. A graph was drawn by plotting $1 / \mathrm{X} / \mathrm{m} v s .1 / \mathrm{C}_{\mathrm{eq}}$

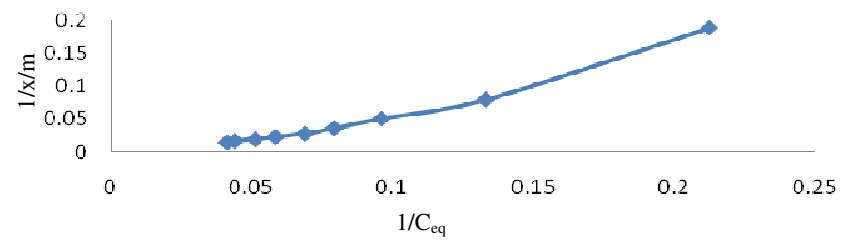

Figure 10. Langmuir adsorption isotherm for PSSC

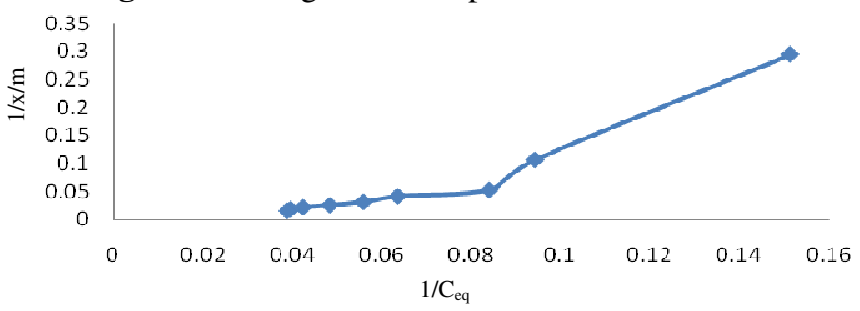

Figure 11. Langmuir adsorption isotherm for CAC

\section{Temkin adsorption isotherm}

The adsorbent- adsorbate interactions were studied by the Temkin isotherm (Figure $12 \& 13$ ). By ignoring the extremely low and large values of concentration, the model assumes that the heat of ion exchange/adsorption of all molecules in the layer would increase linearly rather than the logarithmic with coverage. Its derivation is characterized by a uniform distribution of binding energies which was carried out by plotting the quantity adsorbed $\mathrm{x} / \mathrm{m}$ against $\ln \mathrm{C}_{\mathrm{eq}}$.

\section{Regeneration studies}

Regeneration studies help to elucidate the adsorption nature and to recover metals from water and adsorbent. Attempts were made to regenerate nickel from the adsorbent carbons using $\mathrm{HCl}$ of various strengths ranging from $(0.01-0.10 \mathrm{~N})$. It has been found that concentration of $0.01 \mathrm{~N}$ of $\mathrm{HCl}$ was required to recover $77 \%$ of $\mathrm{PSSC}$ and $75 \%$ of CAC respectively. 


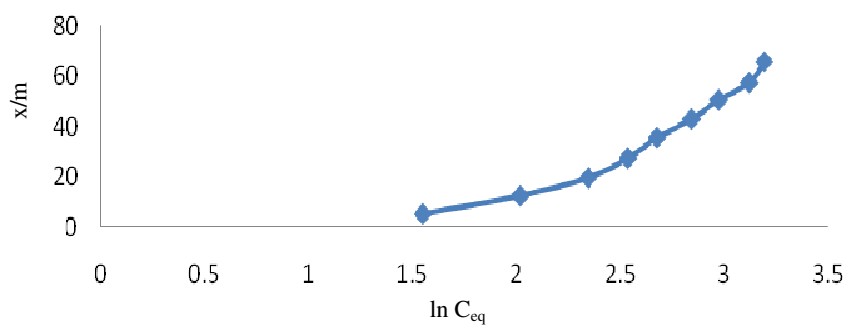

Figure 12. Temkin adsorption isotherm of PSSC

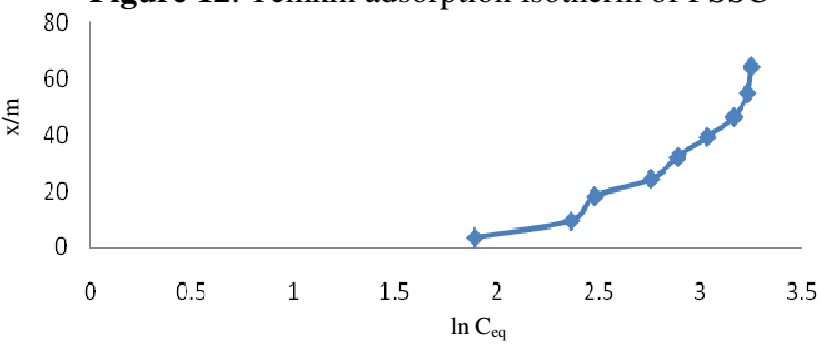

Figure 13. Temkin adsorption isotherm of CAC

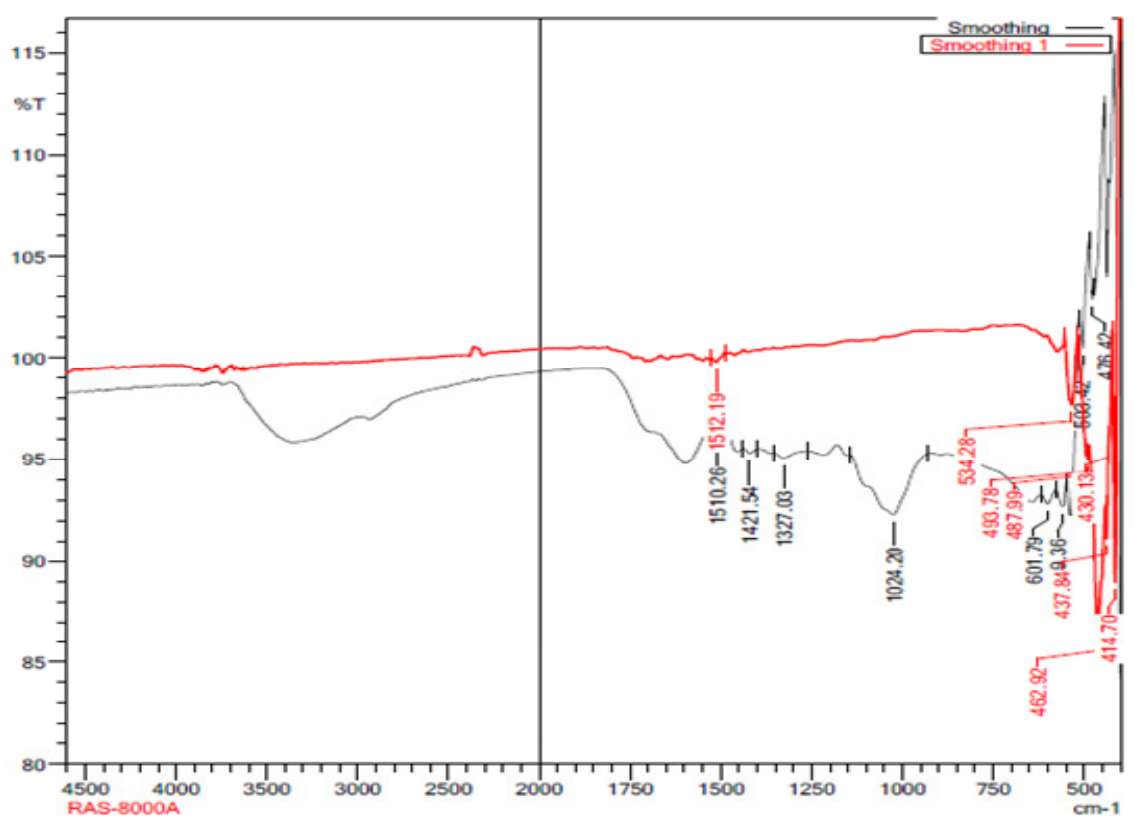

Figure 14. FT IR spectrum of PSSC before and after adsorption

\section{FT-IR spectrum of CAC before and after adsorption}

Figures $14 \& 15$ show the FT-IR spectrum of PSSC and CAC before and after adsorption. The intense band of this figure clearly explains the high adsorption capacity of PSSC and CAC. Spectrum (Figure 14) show the presence of many functional groups which is present in PSSC before and after adsorption. The frequency observed at $1510.26 \mathrm{~cm}^{-1}$ and $1512.19 \mathrm{~cm}^{-1}$ are due to the presence of nitro compounds $\mathrm{N}-\mathrm{O}$ assymmetric stretching. The frequency observed at $601.79 \mathrm{~cm}^{-1}, 534.28 \mathrm{~cm}^{-1}$ may be due to the presence of alkyl halides or Halo 
alkanes. Spectrum (Figure 15) shows the presence of many functional groups which is present in CAC before and after adsorption. The frequency observed at $599.86 \mathrm{~cm}^{-1}, 555.40 \mathrm{~cm}^{-1}$ and $557.50 \mathrm{~cm}^{-1}$ due to the presence of Alkyl halides like C-Cl, C-Br and C-I stretching. Figure 15 spectrum show the frequency observed at $3400-1600 \mathrm{~cm}^{-1}$ may be due to the stretching and bending vibration of $\mathrm{H}_{2} \mathrm{O}$ molecule. Shifting of frequency could not be observed for the PSSC and CAC before and after adsorption. From this we can conclude the functional groups have not been changed for PSSC and CAC before and after adsorption.

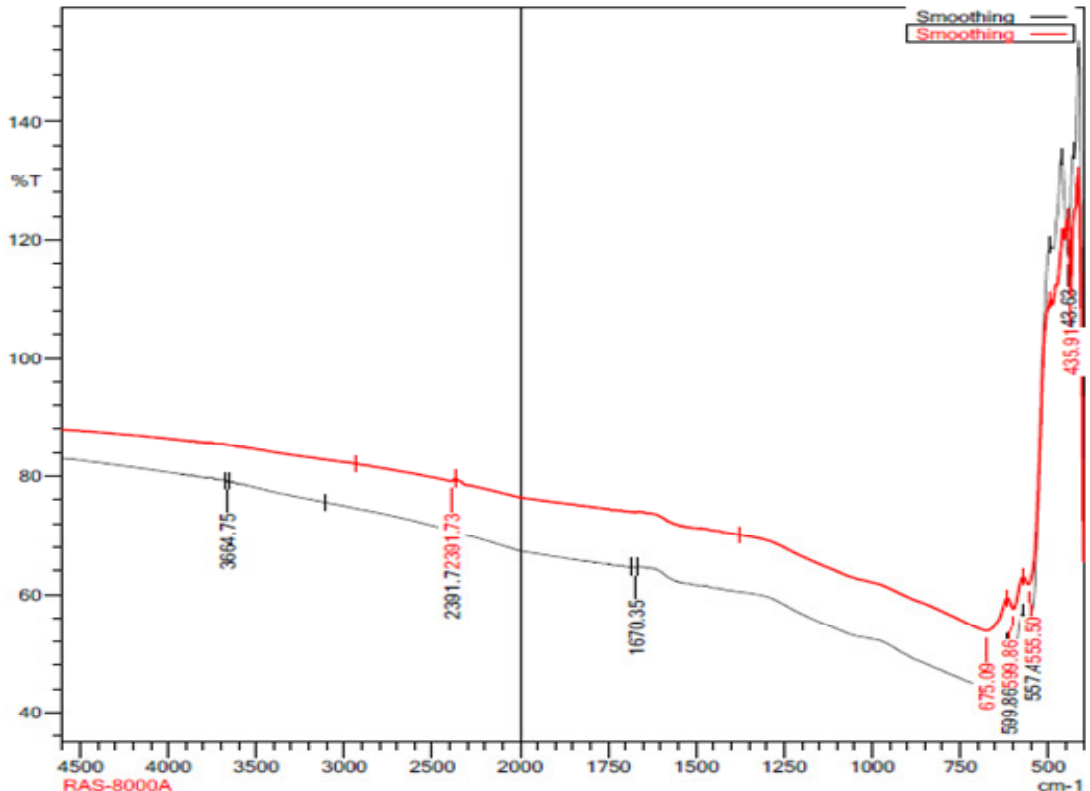

Figure 15. FT IR spectrum of CAC before and after adsorption

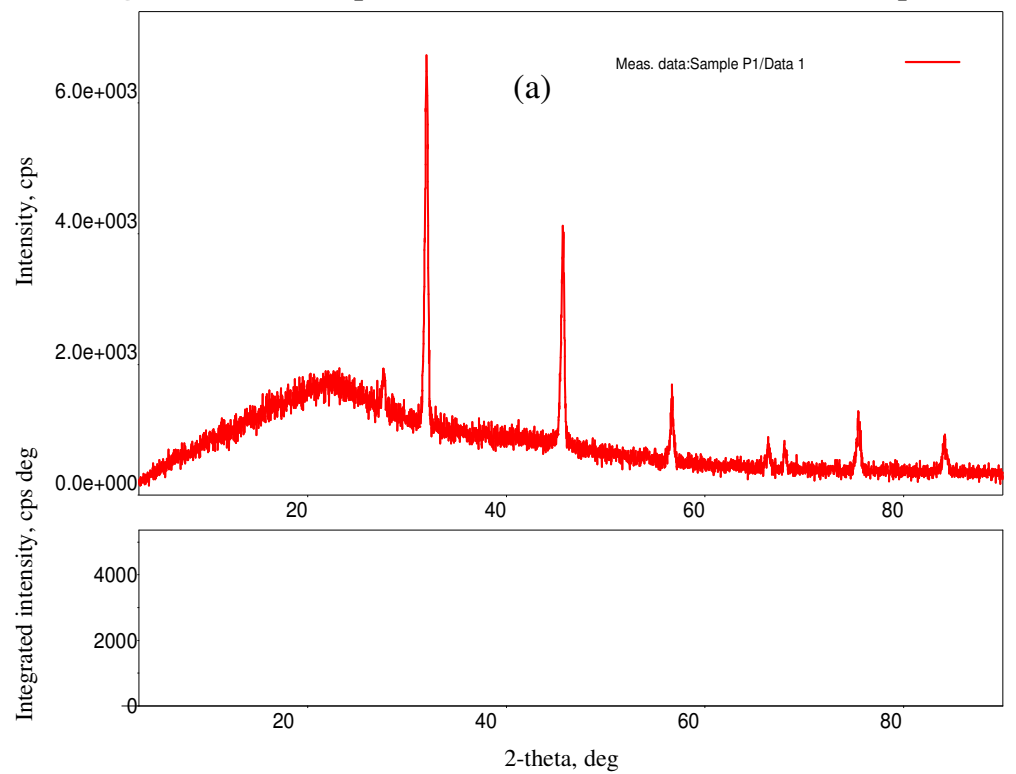




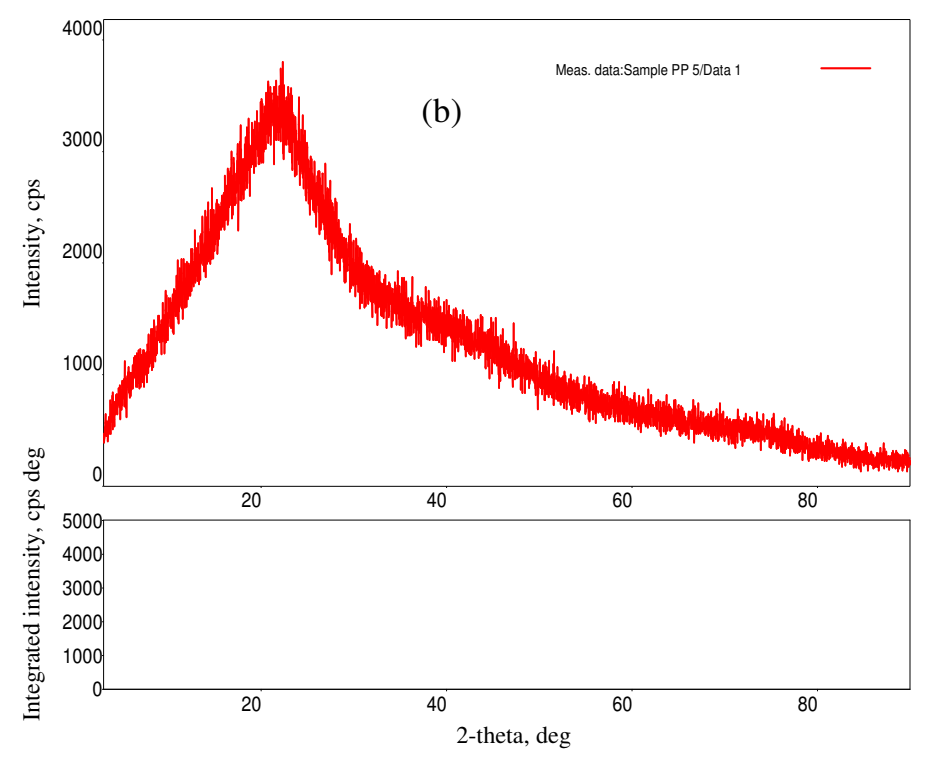

Figure 16. X-ray diffraction spectrum of PSSC before (a) and after (b) adsorption

The XRD pattern of PSSC and CAC for before and after adsorption is shown in Figures $16(\mathrm{a}, \mathrm{b}) \& 17(\mathrm{a}, \mathrm{b})$ there was significant difference observed in Chromium adsorbed PSSC \& CAC compared to non-adsorbed PSSC \& CAC. Cr(VI) adsorbed PSSC \& CAC showed higher intensity of diffraction peaks.

The increment in the crystallite size is may be due to increment in space charge polarization and crystal defects after adsorption. The literature of carbon materials repeatedly refers to the crystal and to the crystal size, with its graphitic connotations, in analyses of structure within activated carbon based on XRD data. The crystalline structure increases the adsorption of metals on to prepared activated carbon, where the metals adsorbed on the upper layer of the crystalline structure of the carbon surface by means of physisorption.

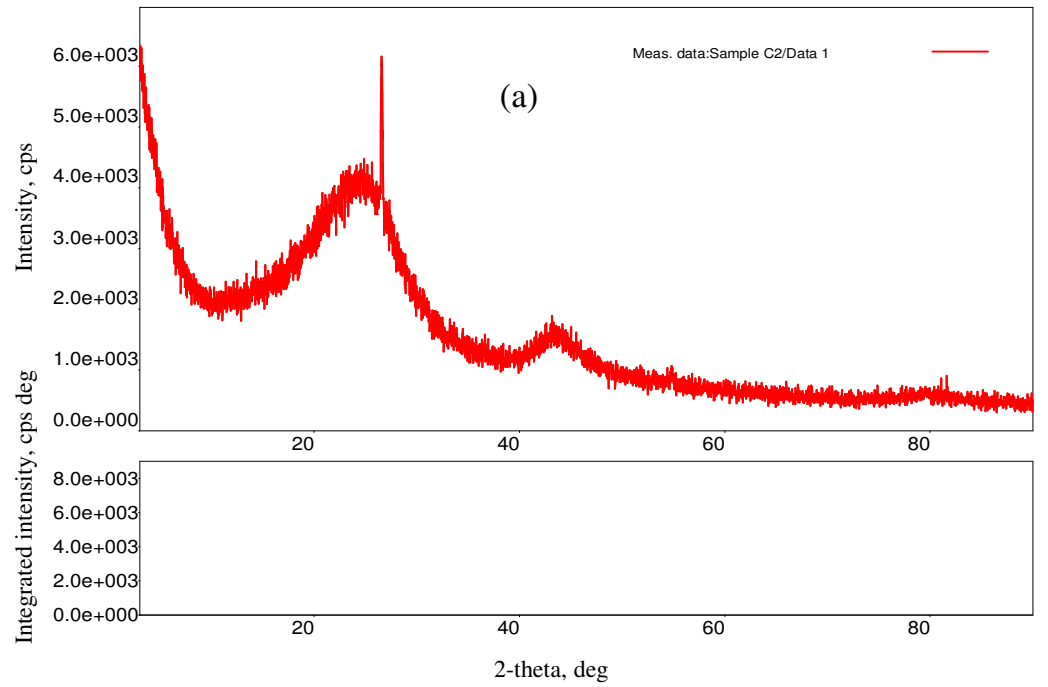




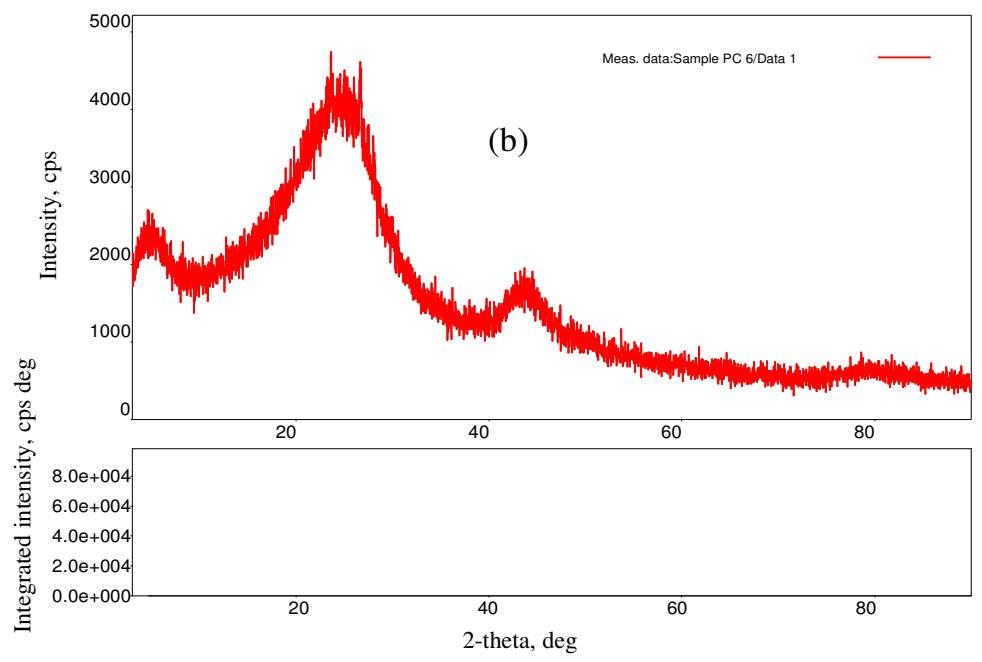

Figure 17. X-ray diffraction spectrum of CAC before (a) and after (b) adsorption

\section{Conclusion}

Investigation from the above studies using the adsorbent as PSSC and CAC, the following conclusions were drawn, since the preparation of PSSC was much easier and pista seeds are abundantly available ass unwanted material, this seed is preferred for the study. From the study of characteristics of PSSC and CAC, PSSC was found to be a better adsorbent. By the batch mode studies it has been concluded that PSSC is better than CAC. Thus it can be concluded that PSSC is economically reliable, cheaper and effective adsorbent in the removal of nickel from wastewater of chemical industries compared to CAC.

\section{References}

1. Ravikrishnan A, Environmental Science and Engineering, Sri Krishna Hitech publishing company, Revised Edition, 2016-17, Pp 37-43.

2. Sharma B K, Environmental chemistry, Goel Publication House, Meerut, Eighth Edition, 2005, Pp 55-67.

3. Srivastava S and Goyal P, Novel Biomaterials, Decontamination of Toxic Metals from Wastewater, 2010, Springer-Verlag. ISBN 978-3-642-11329-1

4. Brandes E A, Greenway H T and Stone H E N, Ductility in Chromium Nature, 1956, 178, 587

5. Baselt R C, Disposition of toxic drugs and chemicals in man, $8^{\text {th }}$ Edition, Biomedical Publications, Foster city CA, 2008 Pp 305-307

6. Selvi V and Jeyanthi G P, Res J Chem Environ., 2004, 8(1), 20-23.

7. $\quad$ Srivatsave R K, Ayachi A K and Mishra M, Poll Res., 2001, 20(4), 639-643.

8. Mohammad Al-Anber, Desalination, 2010, 250(3), 885-891;

DOI:10.1016/j.desal.2009.06.071 